Check for updates

Cite this: RSC Adv., 2017, 7, 21360

\title{
Enhanced saccharification of cellulose and sugarcane bagasse by Clostridium thermocellum cultures with Triton X-100 and $\beta$-glucosidase/ Cellic $\circledast$ CTec2 supplementation
}

\begin{abstract}
Xiao-Su Qu, ${ }^{a}$ Bin-Bin $\mathrm{Hu}^{a}$ and Ming-Jun Zhu (D) *ab
Clostridium thermocellum is the most efficient cellulose-degrading bacterium known for producing cellulosome, which was used to directly degrade sugarcane bagasse (SCB) with limited glucose accumulation. However, the glucose production was significantly enhanced with $0.25 \%$ Triton X-100 and $30 \mathrm{U} \mathrm{g}^{-1}$ of $\beta$-glucosidase supplementation. A glucose accumulation of $21.33 \pm 0.35 \mathrm{~g} \mathrm{~L}^{-1}$ and substrate degradation of $61.91 \pm 0.77 \%$ from $60 \mathrm{~g} \mathrm{~L}^{-1}$ sodium hydroxide-pretreated SCB were reached, with a $609.41 \%$ and $75.53 \%$ increase over the control (3.01 $\left.\pm 0.26 \mathrm{~g} \mathrm{~L}^{-1}, 35.27 \pm 2.91 \%\right)$, respectively. More interestingly, a synergism between $C$. thermocellum cultures and Cellic ${ }^{\circledR}$ CTec2 (30 CBU per g, 1.2 FPU per $g$ substrate) in the enzymolysis of Avicel was observed and the glucose concentration and saccharification ratio of Avicel reached $56.90 \pm 1.20 \mathrm{~g} \mathrm{~L}^{-1}$ and $94.8 \%$ at $60 \mathrm{~g} \mathrm{~L}^{-1}$ Avicel. Moreover, a highest glucose concentration of $83.17 \mathrm{~g} \mathrm{~L}^{-1}$ was achieved at $100 \mathrm{~g} \mathrm{~L}^{-1}$ Avicel. The present work provides an effective and promising process for industrial saccharification of cellulose.
\end{abstract}

Received 28th February 2017

Accepted 4th April 2017

DOI: $10.1039 / \mathrm{c} 7 \mathrm{ra0} 2477 \mathrm{k}$

rsc.li/rsc-advances complex. The scaffoldin subunit contains a single CBM together with numerous cohesion modules and binds strongly to a dockerin module borne by each cellulosomal enzyme. ${ }^{4}$ The cellulosome has been reported more effectively than fungal free enzyme in degrading cellulose. ${ }^{5}$ Moreover, using multi-enzyme complexes, C. thermocellum can saccharify lignocellulose during cultivation, which would greatly reduce operating costs. ${ }^{6}$ Fermentation products generated by $C$. thermocellum are mostly ethanol (low-tolerant generally) and acetic acid and the production of all products besides hydrogen are generally limited. However, the previous research in our laboratory found that the addition of nonionic surfactant (Triton X-100) in $C$. thermocellum cultures resulted in an accumulation in reducing sugars and showed little negative effect on hydrogen production. ${ }^{7,8}$ And the possible reasons of enhancing saccharification by $C$. thermocellum cultures with Triton X-100 addition was also studied before. Triton X-100 showed the detrimental effect on growth and metabolism of $C$. thermocellum, resulting in less transportation and consumption of reducing sugar. On the other hand, Triton X-100 had positive effect on enzyme activity and concentration in the supernatant, indicating that cellulases or cellulosome might be released from cell surface. ${ }^{8}$ However, when a new thermophilic bacterium was used, more glucose was released and a certain amount of cellobiose was detected. In order to optimize the cellulolytic abilities of cellulosomes, it is necessary to eliminate the inhibition of cellobiose. ${ }^{9}$ Thus, there are still many potential aspects that need to be studied to improve the accumulation of reducing sugar including glucose

\footnotetext{
${ }^{a}$ School of Bioscience and Bioengineering, South China University of Technology, Guangzhou Higher Education Mega Center, Panyu, Guangzhou 510006, People's Republic of China. E-mail: mjzhu@scut.edu.cn; Fax: +86 20 39380601; Tel: +86 20 39380623

${ }^{b}$ School of Life and Geographical Sciences, Kashi University, 29 Xueyuan Road, Kashi 844006, Xinjiang Uygur Autonomous Region, People's Republic of China
} 
and xylose. Additionally, most common commercially available cellulases are produced by Trichoderma and Aspergillus species and limited researches ${ }^{7,10,11}$ focus on improving glucose production by $C$. thermocellum cultures. The proteins secreted by cellulolytic fungi are above $20 \mathrm{~g} \mathrm{~L}^{-1}$, but costs are high due to long fermentation time and high power demand for broth aeration. ${ }^{2,12}$ So, a study on combination of cellulosome and fungal cellulase can be performed to reduce the utilization of high-cost commercial cellulase.

Herein, we bring up a promising strategy for the converting SCB and Avicel into glucose and increasing the degradation of substrate further by $C$. thermocellum cultures with nonionic surfactant Triton X-100 and $\beta$-glucosidase supplementation. Moreover, an efficient synergism is found in enzymatic hydrolysis of Avicel, resulting in reducing the cost of utilization of commercial cellulase.

\section{Materials and methods}

\subsection{Substrates, surfactant and enzymes}

SCB was provided by the Guangzhou Sugarcane Industry Research Institute (Guangdong province, China). Alkali pretreatment was performed as described previously in Cheng et al. $^{7}$ Briefly, the SCB was soaked in $3 \%(\mathrm{w} / \mathrm{v}) \mathrm{NaOH}$ solution with a liquid to solid ratio of $25: 1(\mathrm{v} / \mathrm{w})$ and incubated for $3 \mathrm{~h}$ in a water bath at $80{ }^{\circ} \mathrm{C}$. Afterwards, the pretreated SCB was washed into neutral with distilled water and then dried for $48 \mathrm{~h}$ at $60{ }^{\circ} \mathrm{C}$. Finally, the dried SCB was milled and sieved through a 100 mesh screen. The chemical compositions of the pretreated SCB were determined according to the methods of the National Renewable Energy Laboratory. ${ }^{13}$ The main chemical components of the SCB were $59.89 \pm 0.16 \%$ cellulose, $17.99 \pm$ $0.15 \%$ hemicellulose, $8.30 \pm 1.31 \%$ Klason lignin, $2.68 \pm 0.08 \%$ acid soluble lignin and other components. Microcrystalline cellulose Avicel PH 105 was obtained from FMC Corporation (Philadelphia, PA, USA).

Non-ionic surfactant, Triton X-100 was purchased from Sigma (St. Louis, MO, USA) and the concentration used in this study was $0.25 \%(\mathrm{w} / \mathrm{v})$.

Two $\beta$-glucosidases were $\mathrm{BglA}^{\mathbf{1 0 , 1 4}}$ cloned from $C$. thermocellum ATCC 27405 and Cellic®CTec2 provided kindly by Novozymes Corporation. Specifically, DNA encoding the BglA was amplified from $C$. thermocellum strain ATCC 27405 genomic DNA by PCR using $5^{\prime}$-CAGTCCATGGCAAAGATAAC- $3^{\prime}$ for sense prime and 5'-CGAGCTCGAAACCGTTGTTTTTGATTAC-3' for antisense primer (NcoI and SacI sites in italic, respectively). The PCR amplified BglA gene was digested by NcoI/SacI and ligated into pET30a resulting in the final vector p30a- $\beta$ GDs. Expression of the proteins was achieved by adding isopropyl- $\beta$-D-thiogalactopyranoside ( $1 \mathrm{mM}$ final concentration) to midexponential phase cultures of $E$. coli BL21 (DE3) harboring target plasmids with incubation for a further $3 \mathrm{~h}$ at $37{ }^{\circ} \mathrm{C}$. The harvested cell pellets were resuspended in lysis buffer $(50 \mathrm{mM}$ potassium phosphate, $\mathrm{pH}$ 6.0) and ultrasounded in a $50 \mathrm{ml}$ plastic centrifuge tube with an ultrasonic cell disintegrator (SCIENTZ-IID, Ningbo Scientz Biotechnology Co., Ltd, Zhejiang Province, China) of $300 \mathrm{~W}$ ultrasonic power, $5 \mathrm{~s}$ interval time, $4 \mathrm{~s}$ ultrasonic time and 25 min total working time. The samples were kept in an ice bath during the ultrasonic process to prevent overheating $^{\mathbf{1 5}}$ and then centrifuged for $15 \mathrm{~min}$ at $10000 \mathrm{rpm}$ and collected the supernatant as crude enzyme for use. The activity of crude enzyme was 25 CBU per ml. Cellic ${ }^{\circledR C T e c} 2$ had an activity of 110 FPU per $\mathrm{ml}$ and $2743 \mathrm{CBU}$ per $\mathrm{ml}$ measured according to International Union of Pure and Applied Chemistry standard assay. ${ }^{16}$

\subsection{Microorganism and inoculum}

$0.8 \mathrm{~g}$ SCB was added into $50 \mathrm{ml}$ serum bottles and supplemented with $18 \mathrm{ml}$ DSMZ 122 media containing the following (per liter): $1.30 \mathrm{~g}$ of $\left(\mathrm{NH}_{4}\right)_{2} \mathrm{SO}_{4}, 2.60 \mathrm{~g}$ of $\mathrm{MgCl}_{2} \cdot 6 \mathrm{H}_{2} \mathrm{O}, 1.43 \mathrm{~g}$ of $\mathrm{KH}_{2} \mathrm{PO}_{4}, 5.50 \mathrm{~g}$ of $\mathrm{K}_{2} \mathrm{HPO}_{4}, 0.13 \mathrm{~g} \mathrm{CaCl} \cdot 2 \mathrm{H}_{2} \mathrm{O}, 6.00 \mathrm{~g}$ of $\mathrm{Na}_{2}-\beta$ glycerol phosphate $4 \mathrm{H}_{2} \mathrm{O}, 0.25 \mathrm{~g}$ of $\mathrm{L}$-glutathione reduced, $4.50 \mathrm{~g}$ of Yeast extract, $1.10 \mathrm{mg}$ of $\mathrm{FeSO}_{4} \cdot 7 \mathrm{H}_{2} \mathrm{O}$ and $1.00 \mathrm{mg}$ of Na-resazurin. The bottles were crimp-sealed, purged with $\mathrm{N}_{2}$ three times and sterilized by autoclaving at $115{ }^{\circ} \mathrm{C}$ for $20 \mathrm{~min}$. For $10 \%(\mathrm{v} / \mathrm{v})$ inoculation, the bottles were then injected with $2 \mathrm{ml}$ exponential phase cultures grown on $10 \mathrm{~g} \mathrm{~L}^{-1}$ Avicel $\mathrm{PH}$ 105 in DSMZ 122 media. The bottles were incubated in a shaking incubator (C24KC refrigerated incubator shaker, Edison, New Jersey, United States) with temperature controlled at $55^{\circ} \mathrm{C}$ and rotation speed set at $150 \mathrm{rpm}$.

\subsection{Optimization of Triton $\mathrm{X}-100$ addition time and substrate concentration}

To study the addition time of Triton X-100 in C. thermocellum cultures, experiment with various addition times $(0,6,12,18,24$ and $48 \mathrm{~h}$ ) were conducted and the $\mathrm{pH}$ of $C$. thermocellum cultures was measured. Bottles without Triton X-100 addition were used as the control. Similarly, in order to achieve more glucose accumulation, a series of substrate concentration (40, 60,80 and $100 \mathrm{~g} \mathrm{~L}^{-1}$ ) were considered at the optimal addition time.

The concentration of metabolites at endpoint of fermentation was measured by HPLC $^{\mathbf{1 7}}$ using culture supernatant centrifuged at $12000 \mathrm{rpm}$ for $10 \mathrm{~min}$. The residual pellets were collected and dried at $60^{\circ} \mathrm{C}$ until a constant weight and then the degradation ratio of SCB was calculated.

$$
\begin{aligned}
\text { Degradation ratio of SCB }(\%)= & \frac{\mathrm{SCB} \text { weight } \operatorname{loss}(\mathrm{g})}{\text { initial weight of SCB }(\mathrm{g})} \\
& \times 100 \%
\end{aligned}
$$

2.4 Saccharification using $C$. thermocellum cultures with Triton X-100 and BglA or Cellic ${ }^{\circledR C T e c} 2$ supplementation

At optimal addition time of Triton X-100 and substrate concentration, $30 \mathrm{CBU}$ per $\mathrm{g}$ substrate of BglA or Cellic®CTec 2 (containing 1.2 FPU per g substrate) was supplemented directly into $C$. thermocellum cultures by single-use syringe and incubator for another $120 \mathrm{~h}$ at $55{ }^{\circ} \mathrm{C}$ and $150 \mathrm{rpm}$. Meantime, Avicel containing equal glucan content as the SCB at optimal concentration was also considered to study the synergism between $C$. thermocellum cultures and Cellic®CTec2. Several 
Table 1 Detailed addition information on substrate, buffer, inocula, Triton X-100 and $\beta$-glucosidase in different experiment groups

\begin{tabular}{|c|c|c|c|c|c|}
\hline Group & $\begin{array}{l}\text { SCB/Avicel } \\
(\%, w / v)\end{array}$ & $\begin{array}{l}\text { pH } 4.8 \text { sodium citrate buffer } \\
(\mathrm{ml})\end{array}$ & $\begin{array}{l}\text { Inocula } \\
(\%, v / v)\end{array}$ & $\begin{array}{l}\text { Triton X-100 } \\
(\%, w / v)\end{array}$ & $\begin{array}{l}\beta \text {-Glucosidase } \\
\text { (CBU per g) }\end{array}$ \\
\hline$+\mathrm{TX}$ & $6.0 / 3.6$ & - & 10 & 0.25 & - \\
\hline Enzymolysis & $6.0 / 3.6$ & 19.92 & - & - & 30 \\
\hline $\mathrm{enz}+\mathrm{TX}$ & $6.0 / 3.6$ & 19.52 & - & 0.25 & 30 \\
\hline
\end{tabular}

controls were set and detailed addition volume of each component was shown in Table 1.

\section{Results and discussion}

\subsection{Effect of Triton X-100 addition on saccharification of SCB by $C$. thermocellum cultures}

3.1.1 Effect of addition time on SCB degradation and metabolites. Previous study in our laboratory found that nonionic surfactant Triton X-100 could improve the biodegradation of SCB and had little negative effect on hydrogen production. ${ }^{18}$ However, the glucose generation was very limited, only $1.33 \mathrm{~g} \mathrm{~L}^{-1}$ was obtained by $C$. thermocellum cultures at a SCB concentration of $20 \mathrm{~g} \mathrm{~L}^{-1}$. The difference of growth properties, metabolites condition and genome sequence ${ }^{19}$ between two strains (C. thermocellum ATCC 27405 and $C$. thermocellum DSM 1313) might result in the diversity of glucose accumulation.

As described in previous study, addition of Triton X-100 in $C$. thermocellum cultures was primarily used to promote release and detachment of cellulosome from cell and also had a negative influence on the growth and metabolism of cell. ${ }^{8}$ Thus, a suitable time for Triton X-100 addition was important and studied first. As can be seen in Fig. 1(b), the addition time of Triton X-100 showed great influence on glucose accumulation and all tests exhibited a certain degree of increase at different addition time of fermentation except for that at $0 \mathrm{~h}$, which means Triton X-100 addition and inoculum were operated at the same time. As the addition time was prolonged, the glucose accumulation increased rapidly and reached a plateau at $12 \mathrm{~h}$, and with a further extension of the time, the glucose production decreased gradually. With Triton X-100 addition at $12 \mathrm{~h}$, the glucose concentration increased significantly from $3.01 \mathrm{~g} \mathrm{~L}^{-1}$ of the control to $8.84 \mathrm{~g} \mathrm{~L}^{-1}$, resulting in an increase of $193.69 \%$ over the control. Our previous study indicated that Triton X-100 showed the inhibitive or detrimental effect on growth and metabolism of $C$. thermocellum, resulting in less transportation and consumption of reducing sugar. However, Triton X-100 had positive effect on enzyme activity and concentration in the supernatant and saccharification still continued, leading to accumulation of sugars. ${ }^{8}$ In order to eliminate the discrepancy of growth among different batches of the experiment, the addition time of Triton $\mathrm{X}-100$ was associated with the $\mathrm{pH}$ of the cultures. Exactly, when the $\mathrm{pH}$ of the culture reached 5.5-6.0, which meant $C$. thermocellum was during late exponential phase, the optimal time for Triton X-100 addition was determined. $\mathrm{PH}$ of broth as an indicator reflected metabolite production (formate, lactate and acetate) of strain. With a high $\mathrm{pH}$, the cell was during lag to early log phase and limited cellulosomes were produced, accompanied with a low degradation of SCB (Fig. 1(a)). However, when the pH of the culture dropped to a constant value and the cell was during stationary phase like 18, 24 and $48 \mathrm{~h}$, the degradation ratios of SCB were all approximately $50 \%$ while the glucose concentration showed a distinct decrease. This might be due to part of the input
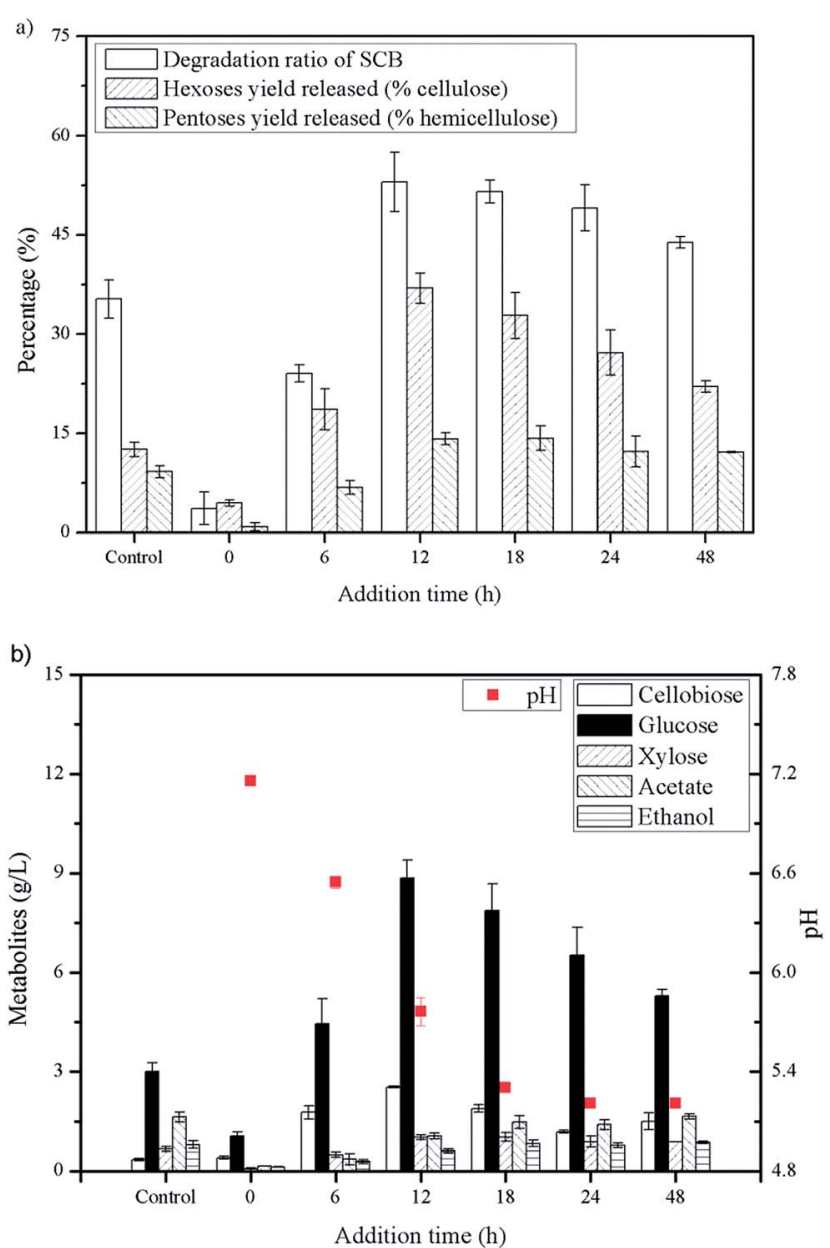

Fig. 1 Impact of Triton X-100 on enzymatic saccharification and metabolite production in biodegradation of sugarcane bagasse. (a) Degradation of SCB, (b) difference of metabolites and $\mathrm{pH}$ of the time point with Triton X-100 added. Control denoted no Triton X-100 added during fermentation process. 
cellulose was utilized in maintaining cellular homeostasis, such as for energy and coproduct production (Fig. 1(b)).

3.1.2 Effect of substrate concentration on SCB degradation and metabolites. In order to increase release of glucose further, the optimal initial substrate concentration was examined, in which the concentration of glucose was chosen as the criterion. As the substrate concentration increased, the inhibition from sugars and degradation products also increased and caused a drop in enzyme efficiency. ${ }^{\mathbf{2 0 1}}$ Also, fibers in pretreated biomass have the capacity to absorb water and as a result require high energy to mix it. Insufficient mixing causes mass transfer issues, leading to lower sugar conversion. ${ }^{3}$ So a suitable substrate concentration should be taken into account. Fig. 2 showed the effects of substrate concentration on the release of glucose from SCB and the degradation of the SCB. When the substrate concentration was below $60 \mathrm{~g} \mathrm{~L}^{-1}$, the glucose concentration reached a $23.03 \%$ increase. While the substrate concentration increased further, it did not ascend anymore and high cellobiose concentration could be observed. Similar to
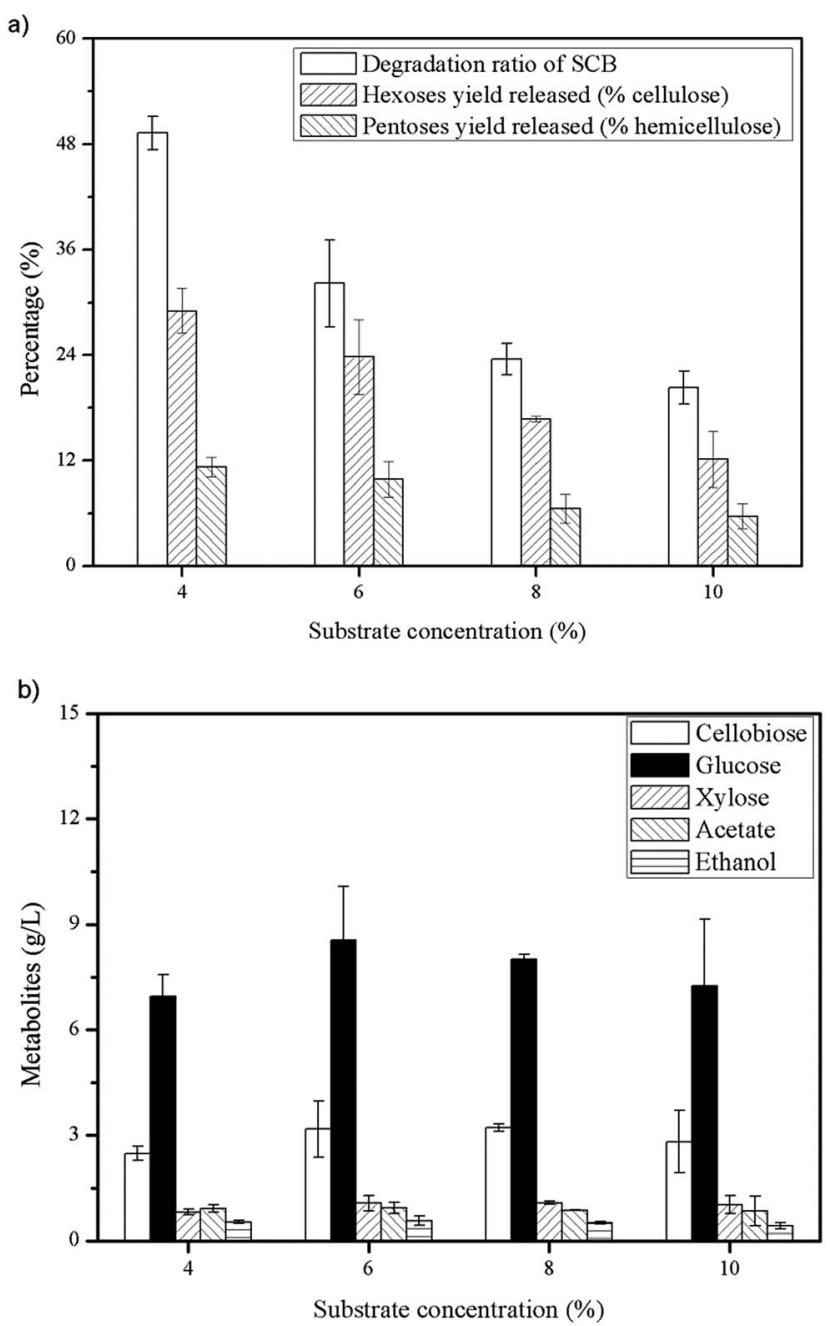

Fig. 2 Profiles of SCB degradation and accumulation of glucose with Triton X-100 added at 12 or $15 \mathrm{~h}(\mathrm{pH}$ 5.5-6.0) during fermentation process at different substrate concentrations. (a) Degradation of SCB, (b) difference of metabolites at different substrate concentration. other fungal and bacterial cellulase systems, the multienzyme cellulosomes of the $C$. thermocellum were also strongly inhibited by the major end product cellobiose. Cellobiose-induced inhibition can be relieved by the addition of exogenous enzyme $\beta$ glucosidase..$^{22,23}$

\subsection{Enhancement of saccharification by $C$. thermocellum cultures with BglA supplementation}

As shown in Fig. 2(b), about $3 \mathrm{~g} \mathrm{~L}^{-1}$ cellobiose was produced in the cultures and in order to relieve cellobiose inhibition and enhance the degradation of cellulose further, a certain amount of $\beta$-glucosidase was needed due to the shortage of this category in cellulosome..$^{9,10}$

In this study, we tested a thermostable $\beta$-glucosidase BglA, which was cloned from $C$. thermocellum ATCC 27405. As can be seen in Fig. 3, when $30 \mathrm{U} \mathrm{g}^{-1}$ of BglA was supplemented with Triton X-100 simultaneously, no cellobiose was detected anymore in the cultures and the glucose concentration increased significantly from 7.58 to $16.09 \mathrm{~g} \mathrm{~L}^{-1}$ (an increase of $112.27 \%$ ). Meantime, the degradation ratio of SCB and hexoses yield released had a $34.88 \%$ and $112.43 \%$ increase respectively.

\subsection{Synergistic saccharification of cellulose between $C$. thermocellum cultures and Cellic ${ }^{\circledR C T e c 2}$}

With a high level of $\beta$-glucosidase in commercial cellulase of Cellic ${ } \mathrm{CTec} 2$, a study about synergism between $C$. thermocellum cultures and Cellic ${ }^{\circledR C T e c} 2$ in SCB or Avicel degradation was conducted. The $C$. thermocellum cultures with Triton X-100 added alone was assayed as noted above at their optimal conditions. The Cellic ${ }^{\circledR C T e c} 2$ (the same dosage as in C. thermocellum cultures) with or without Triton X-100 added alone was also assayed at their optimal conditions as described in Table 1 in the methods section. Interestingly, the results showed that the combination of $C$. thermocellum cultures and Cellic ${ }$ CTec 2 exhibited the synergism on Avicel rather than SCB tested. The final glucose concentration of three groups, namely C. thermocellum culture with Triton X-100 addition, Cellic ${ }^{\circledR} \mathrm{C}-$ Tec 2 with Triton X-100 addition and combination of both were

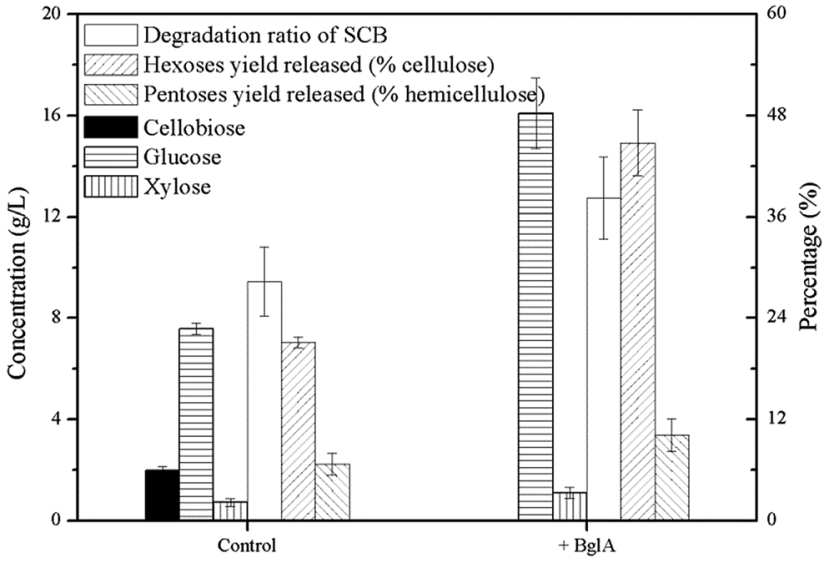

Fig. 3 Enzymatic hydrolysis of $6 \%$ SCB by $C$. thermocellum cultures with Triton X-100 and 30 CBU per g of BglA supplementation. 

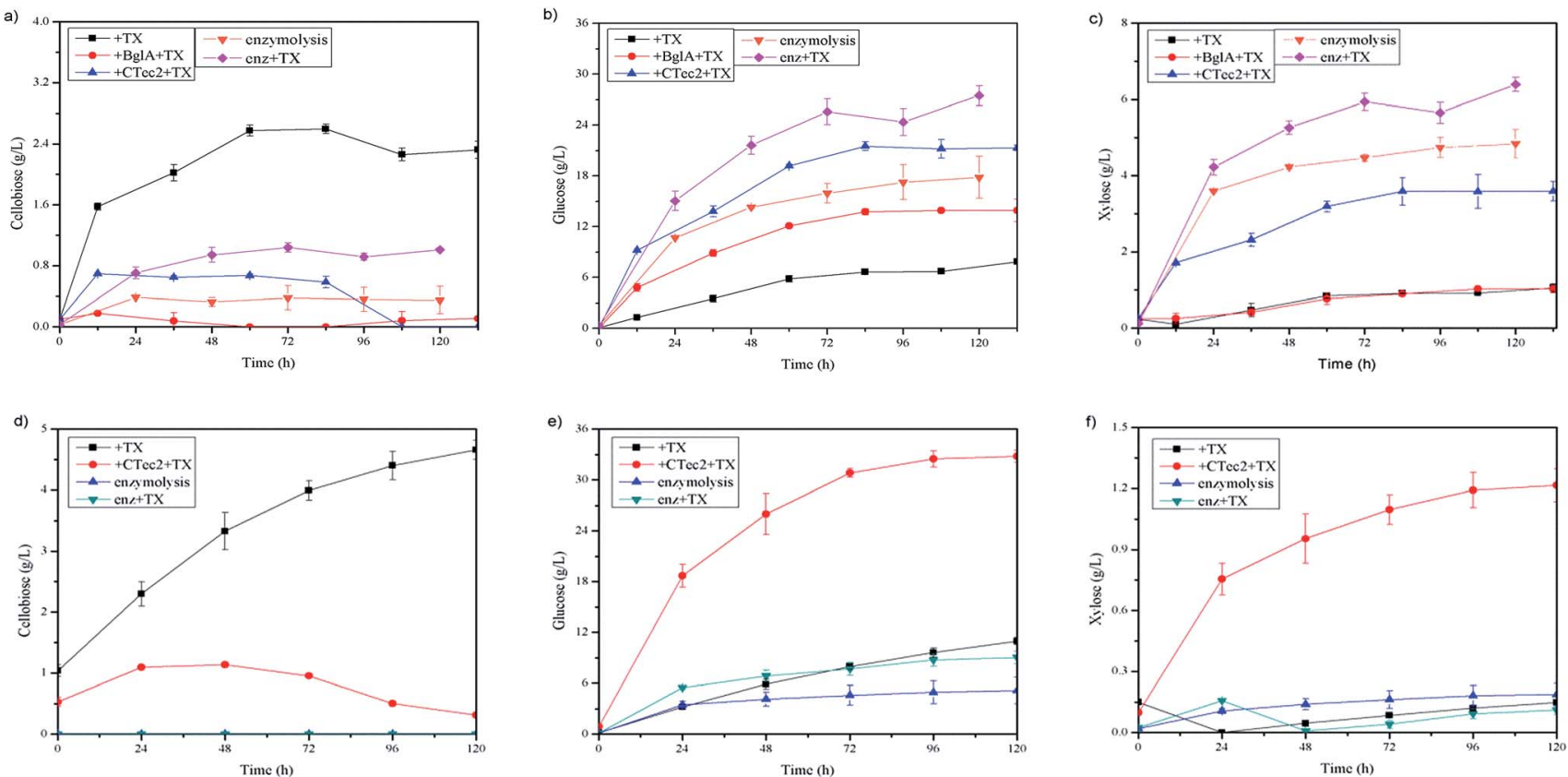

Fig. 4 Study on the synergism between C. thermocellum cultures and CTec2 in enzymatic hydrolysis. With $6 \%$ SCB as substrate, concentration change of (a) cellobiose (b) glucose and (c) xylose. With 3.6\% Avicel as substrate, concentration change of (d) cellobiose (e) glucose and (f) xylose. +TX: enzymatic hydrolysis by $C$. thermocellum cultures with $0.25 \%$ Triton X-100 supplementation; +BglA + TX: enzymatic hydrolysis by C. thermocellum cultures with $0.25 \%$ Triton X-100 and 30 CBU per g of BglA supplementation; +CTec2 + TX: enzymatic hydrolysis by C. thermocellum cultures with $0.25 \%$ Triton X-100 and 30 CBU per g of CTec2 (contains $1.2 \mathrm{FPU}$ per g substrate) supplementation; enzymolysis: enzymatic hydrolysis by $30 \mathrm{CBU}$ per g of CTec2 (contains $1.2 \mathrm{FPU}$ per g substrate); enz + TX: enzymatic hydrolysis by $30 \mathrm{CBU}$ per $\mathrm{g}$ of CTec2 (contains 1.2 FPU per g substrate) and with $0.25 \%$ Triton X-100 supplementation.

10.95, 9.03 and $32.78 \mathrm{~g} \mathrm{~L}^{-1}$, respectively (Fig. 4(e)). Moreover, the initial $(24 \mathrm{~h})$ enzymatic hydrolysis rate were $0.134,0.229$ and $0.799 \mathrm{~g} \mathrm{~L}^{-1} \mathrm{~h}^{-1}$, respectively. A ' $1+1>2$ ' result was reflected between $C$. thermocellum culture and Cellic ${ }^{\circledR C T e c} 2$. However, the synergistic effect was not observed in SCB and the performance of hydrolysis by Cellic®CTec2 (30 CBU per g, 1.2 FPU per g) with Triton X-100 added was superior to the combination of the $C$. thermocellum cultures, Triton X-100 and Cellic®CTec2 (Fig. 4(b)). Furthermore, we noted that in the case of pretreated biomass, fungal cellulases (Cellic ${ }$ CTec2) are superior to cellulosome in enzymatic hydrolysis. While on high purity cellulose like Avicel, cellulosome showed better performance than that of fungal cellulases (Cellic $₫ \mathrm{CTec} 2$ ). The difference may be due to the different physical mechanism of cellulose deconstruction by fungal cellulases and cellulosomes. ${ }^{24}$

High cellulose loading is preferred for industrial processes due to the benefits of lower capital cost and higher production of desirable products. ${ }^{10}$ Thus, to confirm potential of this synergistic system in cellulose saccharification, a series of substrate concentration $\left(60,80,100\right.$ and $\left.150 \mathrm{~g} \mathrm{~L}^{-1}\right)$ was investigated and the saccharification time was extended to $240 \mathrm{~h}$. As shown in Fig. 5, high hexoses yield released of $94.8 \%$ and $89.4 \%$ were obtained in cultures using 60 and $80 \mathrm{~g} \mathrm{~L}^{-1}$ cellulose and $83.17 \mathrm{~g} \mathrm{~L}^{-1}$ glucose was achieved at a cellulose concentration of $100 \mathrm{~g} \mathrm{~L}^{-1}$. More cellobiose was produced again with higher substrate loading and as a result, negative impact on further enzymatic hydrolysis was shown. Thus, in the future, a more

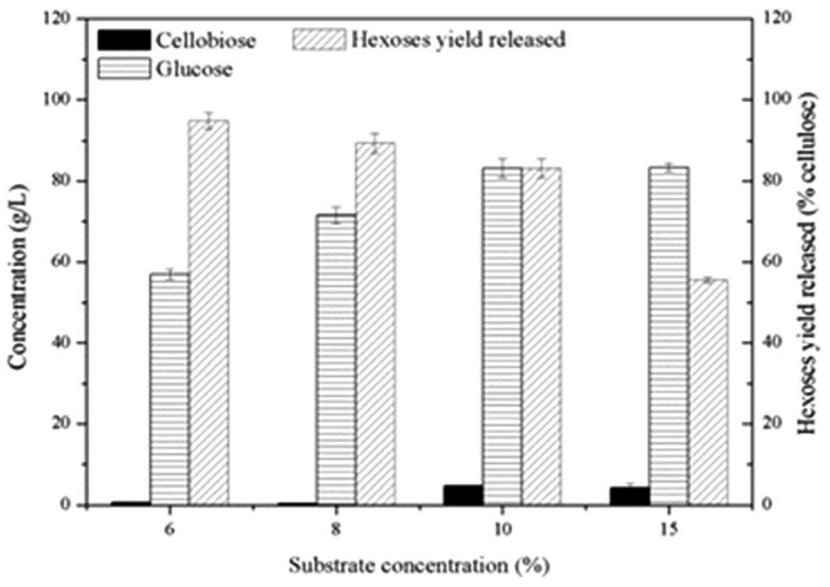

Fig. 5 Glucose and cellobiose accumulation at high Avicel loading by synergistic saccharification between $C$. thermocellum cultures with Triton X-100 (0.25\%) added and CTec2 (30 CBU per g and 1.2 FPU per g substrate).

efficient enzyme of $\beta$-glucosidase can be explored to match well with the $C$. thermocellum cultures and Triton X-100.

\section{Conclusion}

This study established an efficient saccharification system by $C$. thermocellum cultures with Triton $\mathrm{X}-100$ and $\beta$-glucosidase supplementation in lignocellulose degradation. Not only 
increasing biodegradation of SCB but also more glucose accumulation was achieved. Moreover, the synergistic effect on pure cellulose saccharification between $C$. thermocellum cultures, Triton X-100 and Cellic ${ }^{\circledR C T e c} 2$ was observed, leading to greatly increasing saccharification rate with decreasing commercial cellulase utilization. The present study suggested that the $C$. thermocellum cultures could be used for enzymatic hydrolysis directly without further separation and purification.

\section{Acknowledgements}

The authors gratefully acknowledge the financial support of the National Natural Science Foundation of China [grant no. 51478190], Guangdong Provincial Natural Science Foundation Key Project [grant no. 2014A030311014] and Guangzhou Science and Technology Program [grant no. 201510010288 \& 2014Y200047].

\section{References}

1 T. Hasunuma, F. Okazaki, N. Okai, K. Y. Hara, J. Ishii and A. Kondo, Bioresour. Technol., 2013, 135, 513-522.

2 A. V. Gusakov, Trends Biotechnol., 2011, 29, 419-425.

3 V. Balan, ISRN Biotechnol., 2014, 2014, 1-31.

4 E. A. Bayer, R. Lamed and M. E. Himmel, Curr. Opin. Biotechnol., 2007, 18, 237-245.

5 E. A. Johnson, M. Sakajoh, G. Halliwell, A. Madia and A. L. Demain, Appl. Environ. Microbiol., 1982, 43, 1125-1132. 6 T. Sheng, L. Zhao, L. F. Gao, W. Z. Liu, M. H. Cui, Z. C. Guo, X. D. Ma, S. H. Ho and A. J. Wang, Biotechnol. Biofuels, 2016, 9, 1-11.

7 J. Cheng and M. Zhu, Bioresour. Technol., 2013, 144, 623-631. 8 X.-S. Qu and M.-J. Zhu, J. Biobased Mater. Bioenergy, 2016, 10, 362-369.

9 R. Waeonukul, A. Kosugi, C. Tachaapaikoon, P. Pason, K. Ratanakhanokchai, P. Prawitwong, L. Deng, M. Saito and Y. Mori, Bioresour. Technol., 2012, 107, 352-357.
10 P. Prawitwong, R. Waeonukul, C. Tachaapaikoon, P. Pason, K. Ratanakhanokchai, L. Deng, J. Sermsathanaswadi, K. Septiningrum, Y. Mori and A. Kosugi, Biotechnol. Biofuels, 2013, 6, 1-11.

11 H.-N. Lin, B.-B. Hu and M.-J. Zhu, Int. J. Hydrogen Energy, 2016, 41, 2383-2390.

12 S. Brethauer and M. H. Studer, Chimia, 2015, 69, 572-581.

13 D. W. Templeton, E. J. Wolfrum, J. H. Yen and K. E. Sharpless, BioEnergy Res., 2016, 9, 303-314.

14 G. Gefen, M. Anbar, E. Morag, R. Lamed and E. A. Bayer, PNAS, 2012, 109, 10298-10303.

15 H. Zheng, J. Yin, Z. Gao, H. Huang, X. Ji and C. Dou, Appl. Biochem. Biotechnol., 2011, 164, 1215-1224.

16 T. K. Ghose, Pure Appl. Chem., 1987, 59, 257-268.

17 Q. Q. Tian, L. Liang and M. J. Zhu, Bioresour. Technol., 2015, 197, 422-428.

18 J. Cheng, Y. Yu and M. Zhu, Green Chem., 2014, 16, 26892695.

19 L. Feinberg, J. Foden, T. Barrett, K. W. Davenport, D. Bruce, C. Detter, R. Tapia, C. Han, A. Lapidus, S. Lucas, J. F. Cheng, S. Pitluck, T. Woyke, N. Ivanova, N. Mikhailova, M. Land, L. Hauser, D. A. Argyros, L. Goodwin, D. Hogsett and N. Caiazza, J. Bacteriol., 2011, 193, 2906-2907.

20 Y. Lu, Y. Wang, J. C. Guoqian Xu, Y. Zhuang and S. Zhang, Appl. Biochem. Biotechnol., 2008, 160, 360-369.

21 A. G. Cruz, C. Scullin, C. Mu, G. Cheng, V. Stavila, P. Varanasi, D. Xu, J. Mentel, Y.-D. Chuang, B. A. Simmons and S. Singh, Biotechnol. Biofuels, 2013, 6, 1-9.

22 G. Gefen, M. Anbar, E. Morag, R. Lamed and E. A. Bayer, Proc. Natl. Acad. Sci. U. S. A., 2012, 109, 10298-10303.

23 S. Morais, J. Stern, A. Kahn, A. P. Galanopoulou, S. Yoav, M. Shamshoum, M. A. Smith, D. G. Hatzinikolaou, F. H. Arnold and E. A. Bayer, Biotechnol. Biofuels, 2016, 9, 1-12.

24 M. G. Resch, B. S. Donohoe, J. O. Baker, S. R. Decker, E. A. Bayer, G. T. Beckham and M. E. Himmel, Energy Environ. Sci., 2013, 6, 1858-1867. 